\title{
Myocardial ischemic preconditioning upregulated protein 1(Mipu1):zinc finger protein 667 - a multifunctional $\mathrm{KRAB} / \mathrm{C}_{2} \mathrm{H}_{2}$ zinc finger protein
}

\author{
D. $\operatorname{Han}^{1 *}$, C. Zhang ${ }^{1 *}$, W.J. Fan ${ }^{1,2 *}$, W.J. $\operatorname{Pan}^{1}$, D.M. Feng ${ }^{1}$, S.L. $Q u^{1}$ and Z.S. Jiang ${ }^{1}$ \\ ${ }^{1}$ Institute of Cardiovascular Disease, Key Lab for Arteriosclerology of Hunan Province, \\ Post-doctoral Mobile Stations for Basic Medicine, University of South China, \\ Hengyang City, Hunan Province, PR China \\ ${ }^{2}$ The Second Affiliated Hospital, University of South China, Hengyang City, Hunan Province, PR China
}

\begin{abstract}
Myocardial ischemic preconditioning upregulated protein 1 (Mipu1) is a newly discovered upregulated gene produced in rats during the myocardial ischemic preconditioning process. Mipu1 cDNA contains a 1824-base pair open reading frame and encodes a 608 amino acid protein with an N-terminal Krüppel-associated box (KRAB) domain and classical zinc finger $\mathrm{C}_{2} \mathrm{H}_{2}$ motifs in the C-terminus. Mipu1 protein is located in the cell nucleus. Recent studies found that Mipu1 has a protective effect on the ischemia-reperfusion injury of heart, brain, and other organs. As a nuclear factor, Mipu1 may perform its protective function through directly transcribing and repressing the expression of proapoptotic genes to repress cell apoptosis. In addition, Mipu1 also plays an important role in regulating the gene expression of downstream inflammatory mediators by inhibiting the activation of activator protein-1 and serum response element.
\end{abstract}

Key words: Mipu1; Zinc finger structure; Nuclear factor; Transcription and repression

\section{The cDNA encoding early hematopoietic zinc finger protein}

Myocardial ischemic preconditioning upregulated protein 1 (Mipu1) is upregulated during ischemic preconditioning by combining suppression subtractive hybridization and cDNA chip technology. It is currently designated as zinc finger protein 667 (ZNF667) by the Hugo Nomenclature committee and has GenBank accession number AY221750 (1,2). As a zinc finger nuclear transcriptional repressor, Mipu1 inhibits oxidative stress-induced cell injury, which is due to downregulation of expression of the apoptosis-related genes Fas and Bax (2-4). Electrophoretic mobility shift assay (EMSA) and luciferase reporter gene assays showed that hypoxia inducible factor $1 \alpha(\mathrm{HIF}-1 \alpha)$ and CAMP-response element binding protein (CREB) bound to the Mipu1 promoter region and promoted its transcription during oxidative stress in cells $(4,5)$.

The properties of Mipu1/ZNF667 are still only partially understood. However, its molecular features and expression profile as well as the biological functions so far identified suggest that it may play a role in the cardiovascular system. In this overview, we illustrate the data currently available on the structure, expression, interactions, and functional properties of this protein and discuss its possible significance in the cardiovascular field.

\section{Biological characteristics of Mipu1}

\section{Mipu1, a typical N-terminal Krüppel-associated box (KRAB) $/ \mathrm{C}_{2} \mathrm{H}_{2}$ zinc finger protein}

A number of proteins with amino acid motifs capable of recognizing distinct DNA sequences via interaction with hydrogen donors and acceptors located in DNA major and minor grooves have been identified by bioinformatic analysis of DNA binding domains. The zinc finger domain can bind with DNA, the peptide, or histidine in the zinc finger protein and bind with divalent zinc ion to form a specific secondary structure. The zinc finger protein family has many subfamilies, among which $\mathrm{C}_{2} \mathrm{H}_{2}$ (or Kruppel) is the

Correspondence: Shunlin Qu: <qushunlin78@126.com>; Zhisheng Jiang: <zsjiang2005@163.com>.

${ }^{*}$ These authors are co-first authors.

Received April 2, 2014. Accepted July 23, 2014. First published online October 31, 2014. 


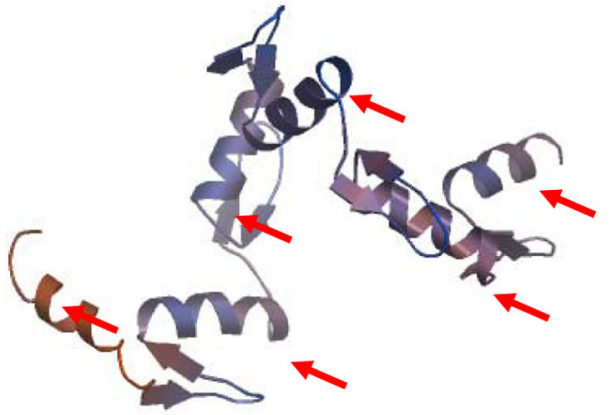

Figure 1. Structure of ZNF667. Arrows: zinc finger structure.

largest subfamily, in which the zinc finger sequence is CX_2CX_3FX_5LX_2HX_3H and the conserved sequence between the two zinc fingers is TGEKP(Y/F)X, where $X$ represents any amino acid between conserved amino acids (6-9). The typical $\mathrm{C}_{2} \mathrm{H}_{2}$ zinc finger is a short protein motif with two histidine and two cysteine residues that hold a zinc ion with coordination bonds. It is obvious at present that they can also recognize various motifs in double-stranded DNA, single-stranded DNA, RNAs, and proteins (10-13). Depending on the domain at the $\mathrm{N}$-terminal, $\mathrm{C}_{2} \mathrm{H}_{2}$ zinc finger proteins can be divided into four categories: FAX (finger-associated boxes), FAR (finger-associated repeats), POZ (pox virus and zinc fingers also known as Zin), and KRAB (Krüppel-associated box). The zinc finger proteins that contain $\mathrm{KRAB}$, also called $\mathrm{KRAB}$ zinc finger proteins (KRAB-containing zinc finger proteins, KZNF), make up almost one-third (290 kinds) of all zinc finger proteins (799 kinds). They are the largest transcription repressor family in mammals and play an important role in embryonic development, cell differentiation, cell transformation, and cell cycle regulation (14-18) (Table 1; 19-27).

The full length of the Mipu1 open reading frame is 1827 base pairs (bp), encoding 608 amino acids; it is composed of five exons and four introns, and maps to chromosome 1q12.1 (2). The N-terminal region of the encoded peptide chain has a KRAB domain, whereas the
C-terminal region has $14 \mathrm{C}_{2} \mathrm{H}_{2}$ zinc fingers; therefore, it is a typical $\mathrm{KRAB} / \mathrm{C}_{2} \mathrm{H}_{2}$ zinc finger protein. The six zinc fingers at the $\mathrm{C}$-terminus of Mipu1 protein have been shown to combine with DNA, and Mipu1 has been identified as a transcription repressor that binds to the specific DNA binding site 5'-TGTCTTATCGAA-3', with CTTA as the key sequence of the binding site $(3,25,28,29)$ (Figure 1).

\section{Promoter region of Mipu1 and its transcriptional regulation}

Two different promoter prediction programs predicted two potential promoter regions for Mipu1: -104 to $+146 \mathrm{bp}$, and -104 to $+36 \mathrm{bp}$, with respect to the transcription start site. Both predicted Mipu1 promoters include the region between -104 and +36 bp, proposed to be the core promoter or the minimal promoter. Seven different deletion constructs were transiently transfected into an $\mathrm{H} 9 \mathrm{c} 2$ cardiomyocyte cell line, and showed the luciferase activity of the seven constructs relative to the promoter-less construct. The results mapped the minimal promoter of Mipu1 to the region between -100 and +1 bp with respect to the transcription start site (30).

Lv et al. (30) showed that the GC box is essential for regulating the constitutive expression of Mipu1. However, the GC box has neither hypoxia-response nor stressresponse elements, implying that other transcription factor binding sites within the Mipu1 promoter region might be responsible for its upregulation during pathological stress (ischemic or hypoxic stress). One CREB binding site and one hypoxia response element (HRE) site were identified using the MatInspector software (http://www.genomatix.de/cgi-bin/matinspector_prof/ mat_fam.pl). Our previous studies showed that hypoxiareoxygenation or $\mathrm{H}_{2} \mathrm{O}_{2}$-mediated inducible expression of Mipu1 is partially due to the activation of CREB $(5,31)$. Recently using EMSA and luciferase reporter gene assays, Wang et al. (4) showed that HIF-1 $\alpha$ bound to the HRE within the Mipu1 promoter region and promoted its transcription.

Table 1. Role of $\mathrm{C} 2 \mathrm{H} 2 \mathrm{ZNF}$.

\begin{tabular}{|c|c|c|c|}
\hline $\mathrm{C} 2 \mathrm{H} 2 \mathrm{ZNF}$ & Role & Evidence for the role & Reference \\
\hline ZNF139 & Increased multi-drug resistance & $\begin{array}{l}\text { Promoting the expression of } b c l-2 \text { and } \\
\text { inhibiting the expression of } B a x\end{array}$ & 19 \\
\hline ZNF268 & Contributes to cervical carcinogenesis & Enhancing NF-Kb signaling & 20 \\
\hline \multirow[t]{2}{*}{ ZNFD } & Transcriptional activator in PKC signal pathway & Activates the transcriptional activities of AP1 & 21 \\
\hline & Development of mouse testis & Transcriptional regulation of HSE & 22 \\
\hline \multirow[t]{2}{*}{$\mathrm{HNF}-4 \alpha$} & Regulation of fatty acid metabolism & $\begin{array}{l}\text { Regulating human intestinal fatty acid } \\
\text { binding protein (hFABP2) expression }\end{array}$ & 23 \\
\hline & Regulation of bile acid synthesis in human liver & $\begin{array}{l}\text { Regulation of expression of cholesterol } \\
7 \alpha \text {-hydroxylase (Cyp7a1) }\end{array}$ & 24 \\
\hline ZNF667 & Regulation of cell apoptosis & Repress expression of Fas and Bax & $25-27$ \\
\hline
\end{tabular}

ZNF: zinc finger; HNF-4 $\alpha$ : hepatocyte nuclear factor $4 \alpha$. 


\section{Expression of Mipu1}

Mipu1 mRNA is expressed in the heart, liver, spleen, lung, kidney, intestine, brain, and skeletal muscle of normal mice, with the highest level of expression in spleen and lung, a very high level of expression in heart and skeletal muscle, a very low level of expression in liver and brain, and the lowest level of expression in intestine. Mipu1 protein has a very high level of expression in the heart and liver of normal rats and is mainly located in the nuclei of H9c2 myogenic cells, but it has a very low level of expression in liver, testis, kidney, and skeletal muscle and shows no signs of expression in spleen and lung $(25,32,33)$. In studies of rat myocardial ischemia-reperfusion, Mipu1 expression increased at $3 \mathrm{~h}$ of reperfusion, following $30 \mathrm{~min}$ of myocardial ischemia, reached its peak level $6 \mathrm{~h}$ later, and maintained that level until a further $12 \mathrm{~h}$ later. In addition, Mipu1 expression in H9c2 cells could be induced by hydrogen peroxide (26), and it had an obviously higher expression in cerebral cortex and hippocampus after 12 and $24 \mathrm{~h}$ of reperfusion, after $3 \mathrm{~min}$ of ischemic preconditioning, than that of the sham surgery groups $(32,34)$. Our results indicated that Mipu1 mRNA expression was significantly increased during hypoxia-reoxygenation or $\mathrm{H}_{2} \mathrm{O}_{2}$ stimulation in $\mathrm{H} 9 \mathrm{c} 2$ cells $(5,31)$.

\section{Cytoprotection effects of Mipu1}

It has been demonstrated that Mipu1 has a high expression in rat heart and is mainly located in the nuclei of H9c2 myogenic cells (25). The expression pattern and nuclear localization suggest that Mipu1 plays a role in the regulation of gene transcription in the cardiovascular system. Upregulation of Mipu1 is induced after myocardial infarction mainly in the infarcted area, and to some extent in the remote noninfarcted myocardium, suggesting that it may play an important role in myocardial infarction; however, further studies are needed to identify the mechanism (26). Overexpression of Mipu1 can reduce $\mathrm{H} 9 \mathrm{c} 2$ cell injury caused by $\mathrm{CoCl}_{2}$-serum-free culture (1). At the same time, promoter activity and expression of Mipu1 increased significantly during the hypoxia-reoxygenation process, which suggests that it may be involved in the injury of H9c2 cells (1). Being a zinc finger nuclear transcriptional repressor, its DNA binding sequence is 5TGTCTTATCGAA-3, within which CTTA is the core sequence binding site (25). Recent studies have also shown that Mipu1 can reduce apoptosis of $\mathrm{H} 9 \mathrm{c} 2$ induced by $\mathrm{H}_{2} \mathrm{O}_{2}$ and tumor necrosis factor alpha (TNF- $\alpha$ ), and can repress the expression of the apoptosis-related genes Fas and Bax (25-27). Overexpression of Mipu1 represses transcriptional activity of serum response element (SRE) and activator protein-I (AP-1), and inhibition of Mipu1 expression by RNAi can increase the transcriptional activity of SRE and AP-1; that is, Mipu1 may be involved in the function of SRE and AP-1 during the transcriptional regulation process and plays an important role in the pathological process of heart and vascular diseases through regulating the mitogen-activated protein kinase (MAPK) signaling pathway (35).

HIF-1 serves as an important endogenous cytoprotective gene that maintains oxygen homeostasis by inducing the expression of cluster genes, such as EPO, HO-1, and iNOS, at the transcriptional level (36-40). Recently, Wang et al. (4) reported that HIF-1 $\alpha$ bound to the HRE within the Mipu1 promoter region and promoted its transcription, leading to cytoprotection of HIF-1 against $\mathrm{H}_{2} \mathrm{O}_{2}$-mediated injury in $\mathrm{H} 9 \mathrm{c} 2$ cells partly through regulation of Mipu1 expression. Our previous studies also found that hypoxia-reoxygenation or $\mathrm{H}_{2} \mathrm{O}_{2}$-induced upregulation of Mipu1 in H9c2 cardiomyocytes was mediated by CAMP/ protein kinase $A(P K A)$-dependent CREB activation, and that the cytoprotection of CREB against hypoxia-reoxygenation or $\mathrm{H}_{2} \mathrm{O}_{2}$-mediated injury in $\mathrm{H} 9 \mathrm{c} 2$ cells occurs partly through regulation of Mipu1 expression (5).

Expression of Mipu1 is markedly increased in endotoxemia, which may have an important role in the inflammatory reaction process induced by lipopolysaccharide (LPS) (41). Further analysis of the role of Mipu1 and its mechanism in the inflammatory process caused by LPS may provide new ideas and experimental clues for the prevention and cure of sepsis and other related diseases.

\section{Perspectives}

In summary, Mipu1 is a nuclear factor with a variety of biological functions, such as participation in the process of myocardial ischemic preconditioning, protection of the myocardium from ischemic disease, and inflammation. Analysis of the function of Mipu1 in ischemic heart disease is beneficial because it may provide new ideas for clinical treatment and prevention of ischemic heart disease. However, further development of related technologies is needed to obtain a comprehensive and detailed understanding of the function of Mipu1 and its role in ischemic-related diseases.

\section{Acknowledgments}

Research supported by the National Natural Science Foundation of China (\#81100212, \#81170277, and \#8110 0106), the PhD Programs Foundation of the Ministry of Education of the People's Republic of China (\#20114324 120004 and \#20124324110003), the China Postdoctoral Science Foundation (\#2012 M511383), the Scientific Research Fund of Hunan Provincial Education Department (\#11C1094 and \#11C1095), the Science and Technology Project of Hunan Province (\#2014FJ3014), the Aid Program for Science and Technology Innovative Research Team in Higher Educational Institutions of Hunan Province (\#2008-244), and the Construct Program of the Key Discipline in Human Hunan Province (\#2011-76). 


\section{References}

1. Lei J, Wang KK, Liu XL, Wang GL, Liu Y, Liu MD, et al. Effect of cobalt chloride on the H9c2 cardiomyocytes new gene Mipu1's expression. Prog Mod Biomed 2011; 1: 30-32, [in Chinese].

2. Yuan $\mathrm{C}$, Zhang HL, Liu Y, Wang QP, Xiao XZ. Cloning and characterization of a new gene Mip1 up-regulated during myocardial ishemia-reperfusion. Prog Biochem Biophys 2004; 31: 231-236, [in Chinese].

3. Lei J, Wang KK. Study of the effect and mechanism of HIF-1 on the H9c2 cardiomyocytes new gene Mipu1. [Thesis] Changsha: Central South University; 2009 [in Chinese].

4. Wang K, Lei J, Zou J, Xiao H, Chen A, Liu X, et al. Mipu1, a novel direct target gene, is involved in hypoxia inducible factor 1-mediated cytoprotection. PLoS One 2013; 8: e82827, doi: 10.1371/journal.pone.0082827.

5. Qu S, Zhu H, Wei X, Zhang C, Jiang L, Liu Y, et al. Oxidative stress-mediated up-regulation of myocardial ischemic preconditioning up-regulated protein 1 gene expression in $\mathrm{H} 9 \mathrm{c} 2$ cardiomyocytes is regulated by cyclic AMP-response element binding protein. Free Radic Biol Med 2010; 49: 580-586, doi: 10.1016/j.freeradbiomed. 2010.05.004.

6. Klug A, Schwabe JW. Protein motifs 5. Zinc fingers. FASEB J 1995; 9: 597-604.

7. Messina DN, Glasscock J, Gish W, Lovett M. An ORFeomebased analysis of human transcription factor genes and the construction of a microarray to interrogate their expression. Genome Res 2004; 14: 2041-2047, doi: 10.1101/gr. 2584104.

8. Emerson RO, Thomas $\mathrm{JH}$. Adaptive evolution in zinc finger transcription factors. PLoS Genet 2009; 5: e1000325, doi: 10.1371/journal.pgen.1000325.

9. Fulton DL, Sundararajan S, Badis G, Hughes TR, Wasserman WW, Roach JC, et al. TFCat: the curated catalog of mouse and human transcription factors. Genome Biol 2009; 10: R29, doi: 10.1186/gb-2009-10-3-r29.

10. Brayer KJ, Kulshreshtha S, Segal DJ. The protein-binding potential of $\mathrm{C} 2 \mathrm{H} 2$ zinc finger domains. Cell Biochem Biophys 2008; 51: 9-19, doi: 10.1007/s12013-008-9007-6.

11. Brayer KJ, Segal DJ. Keep your fingers off my DNA: proteinprotein interactions mediated by $\mathrm{C} 2 \mathrm{H} 2$ zinc finger domains. Cell Biochem Biophys 2008; 50: 111-131, doi: 10.1007/ s12013-008-9008-5.

12. Cass D, Hotchko R, Barber $P$, Jones $K$, Gates DP, Berglund JA. The four $\mathrm{Zn}$ fingers of MBNL1 provide a flexible platform for recognition of its RNA binding elements. BMC Mol Biol 2011; 12: 20, doi: 10.1186/1471-2199-12-20.

13. Brown RS. Zinc finger proteins: getting a grip on RNA. Curr Opin Struct Biol 2005; 15: 94-98, doi: 10.1016/j.sbi. 2005.01.006.

14. Shimanuki M, Uehara L, Pluskal T, Yoshida T, Kokubu A, Kawasaki $Y$, et al. KIf1, a $\mathrm{C} 2 \mathrm{H} 2$ zinc finger-transcription factor, is required for cell wall maintenance during long-term quiescence in differentiated G0 phase. PLoS One 2013; 8: e78545, doi: 10.1371/journal.pone.0078545.

15. Thomas JH, Schneider S. Coevolution of retroelements and tandem zinc finger genes. Genome Res 2011; 21: 18001812, doi: 10.1101/gr.121749.111.

16. Zeng Y, Wang W, Ma J, Wang X, Guo M, Li W. Knockdown of ZNF268, which is transcriptionally downregulated by GATA-1, promotes proliferation of K562 cells. PLoS One 2012; 7: e29518, doi: 10.1371/journal.pone.0029518.

17. Liu $Y$, Olanrewaju $Y O$, Zhang $X$, Cheng $X$. DNA recognition of 5-carboxylcytosine by a Zfp57 mutant at an atomic resolution of 0.97 A. Biochemistry 2013; 52: 9310-9317, doi: 10.1021/bi401360n.

18. Villarejo A, Cortes-Cabrera A, Molina-Ortiz P, Portillo F, Cano A. Differential role of Snail1 and Snail2 zinc fingers in E-cadherin repression and epithelial to mesenchymal transition. J Biol Chem 2014; 289: 930-941, doi: 10.1074/ jbc.M113.528026.

19. Li Y, Tan BB, Zhao Q, Fan LQ, Liu Y, Wang D. Regulatory mechanism of ZNF139 in multi-drug resistance of gastric cancer cells. Mol Biol Rep 2014; 41: 3603-3610, doi: 10.1007/s11033-014-3224-4.

20. Wang W, Guo M, Hu L, Cai J, Zeng Y, Luo J, et al. The zinc finger protein ZNF268 is overexpressed in human cervical cancer and contributes to tumorigenesis via enhancing NFkappaB signaling. J Biol Chem 2012; 287: 42856-42866, doi: $10.1074 / j b c . M 112.399923$.

21. Lei C, Liu Q, Wang W, Li J, Xu F, Liu Y, et al. Isolation and characterization of a novel zinc finger gene, ZNFD, activating AP1(PMA) transcriptional activities. Mol Cell Biochem 2010; 340: 63-71, doi: 10.1007/s11010-0100401-1.

22. Xu F, Wang W, Lei C, Liu Q, Qiu H, Muraleedharan V, et al. Activation of transcriptional activity of HSE by a novel mouse zinc finger protein ZNFD specifically expressed in testis. Mol Cell Biochem 2012; 363: 409-417, doi: 10.1007/ s11010-011-1193-7.

23. Klapper M, Bohme M, Nitz I, Doring F. The human intestinal fatty acid binding protein (hFABP2) gene is regulated by HNF-4alpha. Biochem Biophys Res Commun 2007; 356: 147-152, doi: 10.1016/j.bbrc.2007.02.091.

24. Abrahamsson A, Gustafsson U, Ellis E, Nilsson LM, Sahlin $\mathrm{S}$, Bjorkhem I, et al. Feedback regulation of bile acid synthesis in human liver: importance of HNF-4alpha for regulation of CYP7A1. Biochem Biophys Res Commun 2005; 330: 395-399, doi: 10.1016/j.bbrc.2005.02.170.

25. Jiang L, Tang D, Wang K, Zhang H, Yuan C, Duan D, et al. Functional analysis of a novel $\mathrm{KRAB} / \mathrm{C} 2 \mathrm{H} 2$ zinc finger protein Mipu1. Biochem Biophys Res Commun 2007; 356: 829-835, doi: 10.1016/j.bbrc.2007.02.138.

26. Wang G, Zuo X, Liu J, Jiang L, Liu Y, Zheng Y, et al. Expression of Mipu1 in response to myocardial infarction in rats. Int J Mol Sci 2009; 10: 492-506, doi: 10.3390/ ijms10020492.

27. Jiang L. Study on the structure and function of the new upregulated gene Mipu1 in the myocardial ischemic preconditioning. [Thesis] Changsha: Central South University; 2007 [in Chinese].

28. Wang GL. Study on the expression pattern of new gene Mipu1 and its effect on cardiomyocytes apoptosis. [Thesis] Changsha: Central South University; 2009 [in Chinese].

29. Yuan D, Yuan XR, Liu Y, Zhao J, Xiao XZ. The subcellular localization of Mipu1 protein in brain astrocytoma. Chinese $J$ Minimal Invas Surg 2006; 12: 164-167, [in Chinese].

30. Lv B, Tang Y, Li X, Wang G, Yuan C, Liu Y, et al. 
Identification and characterization of the minimal promoter of Mipu1: the role of GC boxes in the regulation of basal transcription. Acta Biochim Biophys Sin 2009; 41: 309-315, doi: 10.1093/abbs/gmp019.

31. Qu SL, Guo F, Fan WJ, Zhang C, Zhan XY, Jiang ZS. The change and significance of Mipu1 promoter activity and Mipu1 mRNA expressiom in myocardial hypoxia reoxygenation injury. Shangdong Med 2012; 52: 5-7.

32. Jiang L, Zhang B, Wang G, Wang K, Xiao X. Expression, purification and characterization of rat zinc finger protein Mipu1 in Escherichia coli. Mol Cell Biochem 2009; 328: 137144, doi: 10.1007/s11010-009-0083-8.

33. Wang G, Zuo X, Jiang L, Wang K, Wei X, Zhang B, et al. Tissue expression and subcellular localization of Mipu1, a novel myocardial ischemia-related gene. Braz J Med Biol Res 2010; 43: 43-51, doi: 10.1590/S0100-879X2009005000010.

34. Yuan D. Expression of brain ischemic preconditioning related new gene Mipu1, subcellular localization and mouse homologous gene clone. [Thesis]: Changsha: Central South University; 2006 [in Chinese].

35. Wang G, Zuo X, Yuan C, Zheng Y, Jiang L, Song J, et al. Mipu1, a novel rat zinc-finger protein, inhibits transcriptional activities of AP-1 and SRE in mitogen-activated protein kinase signaling pathway. Mol Cell Biochem 2009; 322: 93-102, doi: 10.1007/s11010-008-9944-9.

36. Cai Z, Manalo DJ, Wei G, Rodriguez ER, Fox-Talbot K, Lu $\mathrm{H}$, et al. Hearts from rodents exposed to intermittent hypoxia or erythropoietin are protected against ischemia-reperfusion injury. Circulation 2003; 108: 79-85, doi: 10.1161/01.CIR. 0000078635.89229.8A

37. Jelkmann W. Regulation of erythropoietin production. $J$ Physiol 2011; 589: 1251-1258, doi: 10.1113/jphysiol. 2010.195057.

38. Jung F, Palmer LA, Zhou N, Johns RA. Hypoxic regulation of inducible nitric oxide synthase via hypoxia inducible factor-1 in cardiac myocytes. Circ Res 2000; 86: 319-325, doi: 10.1161/01.RES.86.3.319.

39. Ong SG, Hausenloy DJ. Hypoxia-inducible factor as a therapeutic target for cardioprotection. Pharmacol Ther 2012; 136: 69-81, doi: 10.1016/j.pharmthera.2012.07.005.

40. Lee PJ, Jiang BH, Chin BY, Iyer NV, Alam J, Semenza GL, et al. Hypoxia-inducible factor-1 mediates transcriptional activation of the heme oxygenase- 1 gene in response to hypoxia. J Biol Chem 1997; 272: 5375-5381, doi: 10.1074/ jbc.272.9.5375.

41. Gao M, Wang $\mathrm{H}$. The study of Mipu1 gene expression in tissues of mice with endotoxemia. Life Sci Res 2010; 14: 331-334. 